\title{
Metástasis vertebrales como forma de presentación de un Adenocarcinoma Gástrico
}

\author{
Spine metastasis as an initial presentation of Gastric Adenocarcinoma
}

\author{
Carla Falcão, Pedro Neves Tavares,Catarina Duarte Santos,Diana Fernandes \\ Serviço de Medicina, Centro Hospitalar de Leiria, Leiria, Portugal
}

\begin{abstract}
RESUMEN
Las metástasis óseas en el cáncer gástrico son poco frecuentes y normalmente se detectan como recurrencia de un tumor 0 en estadios avanzados de la enfermedad. Por ello, esta forma de presentación en un adenocarcinoma gástrico es infrecuente. Presentamos el caso de una paciente de 82 años con historia de dolor lumbar de larga evolución y ausencia de síntomas gastro-intestinales. Una tomografía lumbar identificó múltiples lesiones osteolíticas y tras estudios complementarios se encontró un adenocarcinoma gástrico como tumor primario. Se inició tratamiento paliativo con radioterapia y de soporte.
\end{abstract}

Palabras clave: Metástasis vertebrales, Adenocarcinoma Gástrico.

\section{INTRODUCTION}

Metastatic spread to the spine is common in advanced stages of cancer but sometimes they emerge as the initial presentation. Usually the most common primary tumors that lead to bone metastasis are prostate, breast, kidney, lung and thyroid cancer ${ }^{1}$. A literature review reported an incidence of bone metastasis in only $0.9-3.8 \%$ of the gastrointestinal cancers and usually in a later stage of the disease or as a recurrence following surgery ${ }^{2}$. Therefore, bone metastasis are even more infrequent as the initial presentation of gastric cancer ${ }^{3}$.

\section{CASE DESCRIPTION}

An 82-year-old woman with a medical history of arterial hypertension and dyslipidemia, was admitted in the emergency department complaining of pain and paresthesia, in the inferior limbs, with progressive worsening in the last 4 months. She denied intermittent claudication, abnormal gait, loss of muscle strength, weight loss, fever, weakness, nausea, vomiting, melena or any other cardiac, respiratory, gastrointestinal or genitourinary symptoms. She did not smoke, nor consumed alcohol and she had no family history of neoplasia. She only mentioned a fall with lumbar trauma 3 years before.

Physical examination was unremarkable, she showed no signs of malnutrition, cachexia, pallor, no palpable organomegaly nor adenomegalies. On neurological examination, she presented positive bilateral Lasègue sign, with symmetrical muscle strength and sensation in the lower limbs, and pain on palpation of the lumbar spine.

A lumbar computed tomography scan (Fig. 1 and 2) was performed and identified a diffused diminished bone density and multiple osteolytic lesions in the lumbar vertebrae of greater extension at $\mathrm{L} 3$, with a collapsed fracture of the ver-

\begin{abstract}
Bone metastasis in gastric cancer is uncommon and usually emerges as a recurrence of cancer and in a later stage of the disease. Therefore, spine metastasis as an initial presentation of gastric adenocarcinoma is a rare event. We present the case of an 82-year-old woman, with a history of prolonged lumbar pain and no gastrointestinal symptoms. A lumbar computed tomography scan identified multiple osteolytic lesions and upon additional investigation we found a Gastric Adenocarcinoma as the primary tumor. She initiated palliative radiotherapy and best supportive care. Keywords: Spine metastasis, Gastric Adenocarcinoma.
\end{abstract}

Fig. 1.

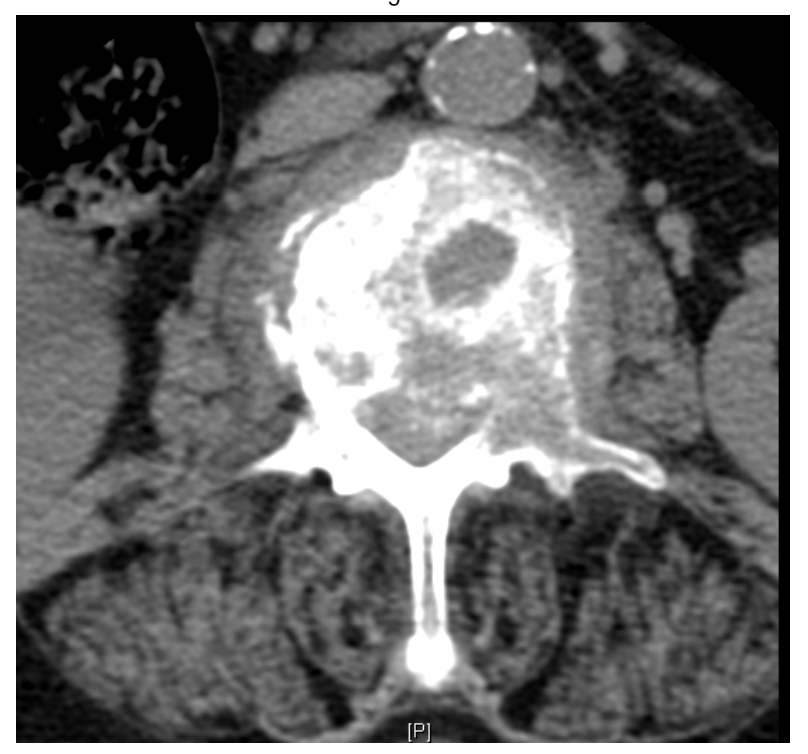

tebral body and lesion of the adjacent paravertebral and epidural soft tissues modulating a moderated spinal stenosis.

She was admitted to the ward for analgesic and conservative treatment and for investigation purposes. Several medical exams were performed in order to determine the primary tumor.

Laboratory workup showed a slightly elevated alkaline phosphatase level (204 U/L) and a normal hemoglobin level, renal function, calcium, inflammatory markers, serum and urinary immunofixation, light chains and immunoglobulin levels. Tumor markers were positive for Carcinoembryonic Antigen (5.2ng/mL), Ca $15.3(24.4 \mathrm{U} / \mathrm{mL})$, Cyfra $21.1(7.8 \mathrm{ng} / \mathrm{mL})$ and highly elevated for Ca 19.9 (89.2 U/mL) and Ca 72.4 (35.4 U/mL). 
Fig. 2

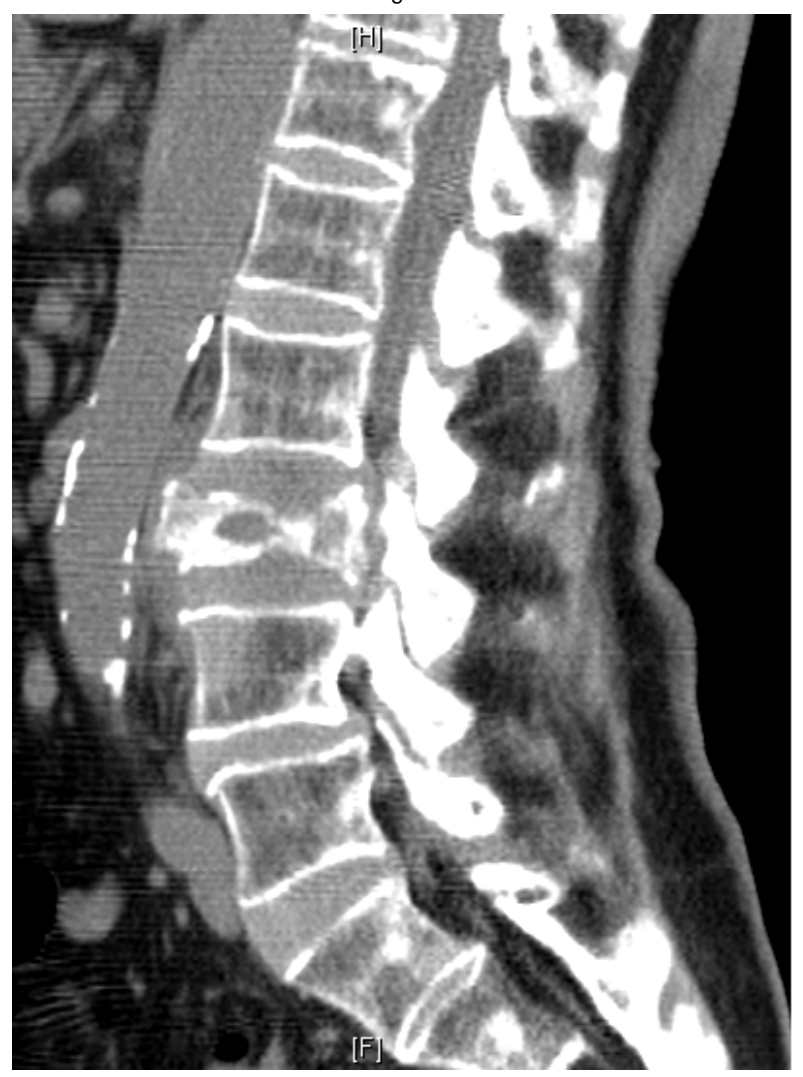

The whole-body computed tomography scan and the bone scintigraphy were negative for other metastasis or primary lesions. Bilateral screening mammograms were negative for breast cancer. Thyroid ultrasound revealed a diffuse heterogeneous thyroid parenchyma and some hypoechogenic nodules with $17 \mathrm{~mm}$ wide on the left lobe and $15 \mathrm{~mm}$ wide on the right lobe. No malignant cells were found at the cytology aspiration biopsy. The gastric endoscopy revealed a small ulcer in the pyloric antrum, that was biopsied, and anatomopathological analysis confirmed an intestinal type gastric adenocarcinoma diagnosis. Presuming the possibility of a synchronous primary bone cancer, a biopsy of the bone lesion was performed, that confirmed the secondary nature of the lesion.

Initial treatment was discussed at a multidisciplinary meeting and with the patient and family, having she refused invasive treatment and accepted only palliative radiotherapy and best supportive care.

\section{DISCUSSION}

Although gastric cancer is reported as the second leading cause of cancer-related deaths worldwide ${ }^{4}$, spine metastasis are rare and portend a worse prognosis, with a median survival of less than 1 year after diagnosis ${ }^{3}$. It usually metastasizes to the liver, lymph nodes, peritoneum and lung ${ }^{5}$. The physiopathological mechanism of the bone metastization is not fully understood. Some case reports imply that the rich supply of blood capillaries in the gastric mucosa may contribute to the early spread of the gastric cancer and the anatomical proximity of the thoracolumbar vertebrae suggests a hematogenous route ${ }^{6}$. After a literature review, we found bone metastasis occur more frequently in cases of Borrmann type 4 advanced Gastric Cancer ${ }^{7}$, poorly differentiated adenocarcinoma, signet ring cell carcinoma or disseminated invasion of locoregional lymph nodes ${ }^{3}$.

A gastric adenocarcinoma as the primary tumor diagnosed in this patient was unexpected, as she had no preceding complaints of gastrointestinal symptoms, suspicious laboratory abnormalities, like anemia, nor locoregional lymph nodes invasion.

This case report demonstrates the importance of a prompt and thorough search for the primary tumor, in patients initially presenting with spine metastasis. When all the regular and most evident investigation procedures fail to find a primary tumor, one should aim for the search of less frequent primary tumors.

\section{REFERENCES}

1. Maccauro G, Spinelli MS, Mauro S, Perisano C, Graci C, Rosa MA. Physiopathology of spine metastasis. Int J Surg Oncol. 2011/08/10. 2011;2011:107969.

2. Gomi D, Fukushima T, Kobayashi T, Sekiguchi N, Sakamoto A, Mamiya K, et al. Gastric cancer initially presenting as bone metastasis: Two case reports and a literature review. Oncol Lett. 2018/09/04. 2018 Nov;16(5):5863-7.

3. Ameur W Ben, Belghali S, Akkari I, Zaghouani H, Bouajina E, Jazia E Ben. Bone metastasis as the first sign of gastric cancer. Pan Afr Med J. 2017 Sep 29;28:95.

4. Jemal A, Bray F, Center MM, Ferlay J, Ward E, Forman D. Global cancer statistics. CA Cancer J Clin. 2011;61(2):69-90.

5. Riihimaki M, Hemminki A, Sundquist K, Sundquist J, Hemminki K. Metastatic spread in patients with gastric cancer. Oncotarget. 2016 Aug;7(32):52307-16.

6. Lehnert T, Erlandson RA, Decosse JJ. Lymph and blood capillaries of the human gastric mucosa. A morphologic basis for metastasis in early gastric carcinoma. Gastroenterology. 1985 Nov;89(5):939-50.

7. Koga S, Takebayashi M, Kaibara N, Nishidoi H, Kimura O, Kawasumi H, et al. Pathological characteristics of gastric cancer that develop hematogenous recurrence, with special reference to the site of recurrence. J Surg Oncol. 1987 Dec;36(4):239-42. 